\title{
Editorial
}

Young Jin Kim ๑, M.D., Ph.D. ${ }^{1}$, Heungsup Sung ๑, M.D., Ph.D. ${ }^{2}$, Chang-Seok Ki $\bullet$, M.D., Ph.D. ${ }^{3}$, and Mina Hur $\odot$, M.D., Ph.D. ${ }^{4}$

\section{COVID-19 Testing in South Korea: Current Status and the Need for Faster Diagnostics}

Coronavirus Disease 2019 (COVID-19) has caused an outbreak in China and is spreading worldwide [1]. As of March 23, 2020, the epidemic has spread exponentially in South Korea, with more than 8,961 patients found positive based on 338,036 tests conducted [2]. In the aftermath of the Middle East respiratory syndrome (MERS) outbreak in 2015, the South Korean Government established a system that enables emergency use authorization (EUA) of in vitro diagnostics (IVDs) for infectious diseases [3]. As a result, South Korea could swiftly approve its first real-time reverse transcription (RT) PCR kit for COVID-19 testing on February 4, 2020 [4], following the country's first reported case of COVID-19 on January 20, 2020 [5]. Shortly after, four additional kits were approved for testing [6]. Currently, 15,000 to 20,000 tests per day are being carried out by national central labs and 95 non-governmental clinical laboratories. These laboratories have been all certified by Korean Society for Laboratory Medicine (KSLM) and have also completed external quality assessments by the Korean Association of External Quality Assessment Service (KEQAS). This issue of Ann Lab Med presents the guidelines for the laboratory diagnosis of COVID-19, which is followed in clinical laboratories in South Korea [6].

As local communities continue to be at risk of the virus spread, on February 23 2020, South Korea raised its national infectious disease alert to the highest level and further mobilized its resources to prevent the spread of COVID-19 [7]. A vast number of real-time RT PCR testing is being carried out thanks to the timely implementation of EUA; however, the country's diagnostic capacity requires further improvement such as addressing the need to shorten the 6-hr turnaround time for testing in situations such as the current COVID-19 crisis. It is also noticeable that a large-scale real-time RT PCR testing is difficult to be implemented in countries with limited resources.

Considering this, what can be done to further improve effectiveness in diagnostic testing? To reduce the spread of COVID-19, the World Health Organization (WHO) has opened its Emergency Use Listing procedure for new submissions; as of February 12, 2020, 220 IVDs have been listed that will be evaluated for analytical sensitivity. Additionally, there are six commercialized near point-of-care (POC) nucleic acid tests (NATs) and nine near-POC NATs under development [8]. However, POC-NATs, developed for rapid diagnosis and use under limited resources, are rarely implemented in outbreak situations caused by novel pathogens. South Korea, despite its robust testing capacity, is no exception to this discrepancy. The Xpert Xpress SARS-CoV-2 (Cepheid, Sunnyvale, CA) and BioFire COVID-19 Test (BioFire Diagnostics, Salt Lake City, UT), which can be tested within 45 minutes, received EUA from the United States FDA as of March 23, 2020 [9]. It is expected to be useful in these urgent situations. In order to cope with other novel infectious diseases that may occur in the future, a system for developing, accrediting, and distributing rapid diagnostic testing,

\section{c) (1) (5)}


such as POC-NATs, should be established.

\section{AUTHORS' DISCLOSURES OF POTENTIAL CONFLICTS OF INTEREST}

No potential conflicts of interest relevant to this article were reported.

\section{ACKNOWLEDGEMENTS}

None.

\section{AUTHOR CONTRIBUTIONS}

YJK, CK, and MH wrote and revised the manuscript; HS served as a scientific advisor and revised the manuscript; all authors reviewed and approved the manuscript.

\section{RESEARCH FUNDING}

None declared.

\section{ORCID}

Young Jin Kim https://orcid.org/0000-0001-8182-2433 Heungsup Sung https://orcid.org/0000-0002-6062-4451

Chang-Seok Ki https://orcid.org/0000-0001-7679-8731

Mina Hur https://orcid.org/0000-0002-4429-9978

\section{REFERENCES}

1. Korean Society of Infectious Diseases, Korean Society of Pediatric Infectious Diseases, Korean Society of Epidemiology, Korean Society for Antimicrobial Therapy, Korean Society for Healthcare-associated Infection
Control and Prevention, Korea Centers for Disease Control and Prevention. Report on the epidemiological features of Coronavirus Disease 2019 (COVID-19) outbreak in the Republic of Korea from January 19 to March 2, 2020. J Korean Med Sci 2020;35:e112.

2. Korea Centers for Disease Control and Prevention. The update of COVID-19 in Korea as of 23 March. http://ncov.mohw.go.kr/tcmBoardView. do?brdld=\&brdGubun=\&dataGubun=\&ncvContSeq=353678\&contSeq =353678\&board_id=\&gubun=ALL (Updated on Mar 23, 2020).

3. Park JS, Choi YS, Yoo CK. Emergency Use Authorization of in-vitro diagnostics for infectious disease. Public Health Weekly Report 2017;10: 555-9.

4. Korea Centers for Disease Control and Prevention. The update of COVID-19 in Korea as of 4 February.http://ncov.mohw.go.kr/tcmBoardView. do?brdld=\&brdGubun=\&dataGubun=\&ncvContSeq=352683\&contSec $=352683 \&$ board_id=\&gubun=ALL (Updated on Feb 4, 2020).

5. Kim JY, Ko JH, Kim Y, Kim YJ, Kim JM, Chung YS, et al. Viral load kinetics of SARS-CoV-2 infection in first two patients in Korea. J Korean Med Sci 2020;35:e86.

6. Hong KH, Lee SW, Kim TS, Huh HJ, Lee J, Kim SY, et al. Guidelines for the Laboratory Diagnosis of COVID-19 in Korea. Ann Lab Med 2020;40:35160 .

7. Korea Centers for Disease Control and Prevention. The update of COVID-19 in Korea as of 23 February. http://ncov.mohw.go.kr/tcmBoardView.do?brdld=\&brdGubun=\&dataGubun=\&ncvContSeq=353064\&con tSeq=353064\&board_id=\&gubun=ALL (Updated on Feb 25, 2020).

8. Foundation for Innovative New Diagnostics. COVID-19 outbreak: diagnostic update. https://www.finddx.org/covid-19/pipeline (Updated on Mar 14, 2020).

9. U.S Food \& Drug Administration, Emergency Use Authorization. https:// www.fda.gov/emergency-preparedness-and-response/mcm-legal-regulatory-and-policy-framework/emergency-use-authorization (Updated on Mar 23, 2020).

Corresponding author: Mina Hur, M.D., Ph.D.

Department of Laboratory Medicine, Konkuk University School of Medicine, Konkuk University Medical Center, 120-1 Neungdong-ro, Hwayang-dong, Gwangjin-gu, Seoul 05030, Korea

Tel: +82-2-2030-5581; Fax: +82-2-2636-6764

E-mail: dearmina@hanmail.net

Key Words: COVID-19, SARS-CoV-2, Korea, Diagnostic testing, Outbreak, Emergency use authorization 